\title{
The Syndrome of Carnitine Deficiency: Morphological and Metabolic Correlations in Two Cases
}

\author{
G. SCARlato, G. PELlEgrini, C. CERRI, G. MEOLA, AND A. VEICSTEINAS
}

\begin{abstract}
SUMMARY: Two cases of systemic carnitine deficiency are described. In both patients, carnitine concentration was lower than normal in serum and muscle tissue. In the first case, the illness began at age 35; the clinical manifestations were only muscular. In the second case, the illness began in childhood; there were intermittent episodes of hepatic enlargement and coma. An excessive lipid content was present in muscle tissue, especially in type I fibers, of both cases, and in the liver of the second patient. Ultrastructural studies of muscle tissue
\end{abstract}

RÉSUMÉ: Nous décrivons deux cas de déficience systémique en carnitine. Chez les 2 patients les concentrations de carnitine étaient plus basses que la normale dans le sérum ê le tissu musculaire. Pour le premier cas la maladie débute à l'âge adulte et les manifestations cliniques sont limitées aux muscles. Le deuxième cas, à évolution fatale, commence dans l'enfance avec épisodes intermittents d'hypertrophie hépatique et de coma. Le tissu musculaire des 2 patients contenait un excès de lipides, surtout dans les fibres de type l. Le foie du second cas était aussi infiltré. Les études au microscope électronique du muscle démontrent revealed important changes of mitochondria.

During muscular exercise, aerobic and anaerobic metabolism were investigated. For a given relative work intensity, these patients showed abnormally high blood lactic acid concentration and lactic acidlpyravic acid ratios. These data, together with the morphological alterations observed in mitochondria, suggest an impaired function of the respiratory chain, leading to a shift of the redlox potential of the tissue towards a non reduced state.

d'importants changements dans les mitochondries.

Nous avons investigué le métubolisme aérobique et anaérobique durant l'exercise musculaire. Il fut ainsi montré que pour an travail d'intensité donnée ces patients ont une concentration d'acide lactique sanguin et un rapport acide lactique/acide pyruvique anormalement élevés. Ces données, ainsi que les altérations morphologiques des mitochondries suggèrent une atteinte de la chaine respiratoire avec une modification du potentiel Redox du tissu vers l'état non réduit.
From the Department of Neurology and the Department of Physiology $\left.(I I)^{\wedge}\right)$, University of Milan, Italy.

Reprint requests to: Prof. Guglielmo Scarlato, Clinica Neurologica, Via F. Sforza, 35, 20122 Milano, Italy.

\section{INTRODUCTION}

In 1973, Engel and Angelini first described a lipid storage myopathy related to a deficiency of serum and muscular carnitine. Since then, a few cases have been published (Markesbery et al., 1974; Vandyke et al., 1975; Karpati et al., 1975; Smyth et al., 1975; Angelini et al., 1976: Boudin et al., 1976; Isaacs et al., 1977; Cornelio et al., 1977; Engel et al., 1977). From these studies, it is possible to recognize two types of carnitine deficiency myopathy. In the first type, the defect is systemic; the final step of carnitine biosynthesis in liver cells is blocked, and the serum level of carnitine is lower than normal. In the second type, carnitine biosynthesis is preserved and serum concentration is within normal limits. but carnitine transport across cell membrane in various tissues such as skeletal muscle, cardiac muscle. Schwann's cell, and leukocytes is impaired. Histochemical and ultrastructural studies of muscle have demonstrated an accumulation of lipid material associated with mitochondrial changes of number, size, shape, and structure. This is a clinical and morphological report of two cases of systemic carnitine deficiency, one of which was fatal. In both patients, aerobic and anaerobic (lactacid) metabolism have been studied, together with some hematochemical parameters, during exercises of increasing loads. This elucidated the relationship between the morphological and biochemical pattern.

\section{CASE REPORTS}

Case 1: C.M., male, 35 years old. In November, 1974, the patient complained of sudden proximal weakness in the lower limbs, which increased with exercise. This worsened in the following months so 
that walking became difficult. In view of the elevated serum creatinephosphokinase (SCPK), glutamic-oxalacetic transaminase (SGOT) glutamic-pyruvic transaminase (SGPT), and a myogenic electromyogram (EMG), polymyositis was diagnosed. Treatment with corticosteroids was started, but without improvement in strength. The weakness progressed, involving the upper limbs both proximally and distally, and cramps appeared in the calves during exercise. The patient was admitted to the Department of Neurology of Milan University in October. 1975.

On admission, the neurological examination revealed weakness and fatigue in the four limbs, proximally, even after slight exercise. Lesser weakness was present distally. The strength of facial, palatal and neck muscles was normal. There were no sensory deficits. Physical examination was otherwise normal. Family history showed no consanguinity between his parents.

\section{Laboratory Results}

The following were within normal limits: blood urea, fasting blood glucose, erythrocyte sedimentation rate, hemogram, glucose tolerance test, serum electrolytes. protein electrophoresis, cholesterol, triglycerides, total lipids, lipoprotein electrophoresis. SCPK was elevated $(201 \mathrm{m \mu} / \mathrm{ml}$, normal range for our laboratory up to 50 ). SGOT was $75 \mathrm{~m} \mu / \mathrm{ml}$ (normal up to 12), SGPT $46 \mathrm{~m} \mu / \mathrm{ml}$ (normal up to 8), and lactic dehydrogenase (LDH) $1810 \mathrm{~m} \mu / \mathrm{ml}$ (normal up to 250 ). Serum carnitine was $1.48 \mathrm{nM} / \mathrm{ml}$ (normal values: 2.5-7nM/ml). Electrocardiogram, chest radiography, and electroencephalogcam were all normal. Electromyography of the left quadriceps, left biceps, and left tibialis anterior was carried out. There was no fibrillation. On voluntary effort, motor unit potentials were of short duration, small amplitude and polyphasic, but in some areas potentials of great amplitude and increased duration were also found. On maximal activity, a reduced recruitment of the motor unit potentials was observed in the quadriceps and tibialis anterior muscles. Motor nerve conduction velocity was normal in the left median nerve $(55.8 \mathrm{~m} / \mathrm{sec})$, but was moderately reduced in the left common peroneal nerve $(43.9 \mathrm{~m} / \mathrm{sec})$.

Treatment with D-L carnitine $(3 \mathrm{~g} /$ day per os) was started. About fifteen days later, the patient began to improve in strength. Three months later he was able to start work again.

Case II: P.T., male, 12 years old. This patient was born after a full term preg- nancy and normal delivery. Milestones of his development were normal until three years of age, when a mild weakness in the lower limbs became evident. Three years later, the weakness worsened, especially in the muscles of neck, limb girdle and trunk, and walking became difficult. There was a spontaneous improvement in the weakness for six months, but at seven years of age he became anorexic and the muscular weakness worsened again. Some months later there was another spontaneous recovery of muscular strength. At 11 years, he was hospitalised with vomiting followed by stupor, coma and severe hypoglycemia. On this occasion the patient had an enlarged liver; he was considered to have a glycogenosis type III. His clinical status improved spontaneously and he remained in good health until March, 1976, when there was a gradual increase in muscular weakness in the four limbs and neck. He was admitted to the Milan University Neurology Department. Family history showed no consanguinity between his parents, and the brother and sister were normal.

On admission, the patient was $150 \mathrm{~cm}$ high and weighed $33 \mathrm{~kg}$. His muscles were hypotrophic, proximally in the upper limbs and distally in the lower ones. Strength was impaired in all limbs: the weakness was severe in the upper limbgirdle and also in the tibialis anterior and peroneus longus and brevis muscles. The muscles of the face and neck were also weak, especially orbicularis palpebralis, flexors of the neck and, sternocleidomastoideus. The muscles were hypotonic; the deep tendon reflexes were depressed on the right side and moderately brisk on the left side. Abdominal reflexes were absent bilaterally and the Babinski sign was present bilaterally. $\mathrm{He}$ had moderate lumbar lordosis and a waddling gait; Gower's sign was negative. The liver was palpable four $\mathrm{cm}$ below the costal margin. The spleen was not palpable. The heart was not enlarged.

\section{Laboratory Results}

The following tests were within normal limits: blood urea, fasting blood glucose, erythrocyte sedimentation rate, glucose tolerance test, serum electrolytes, cholesterol, triglycerides, total lipids, bilirubin, serum creatine-phosphokinase, serum glutamic-oxalacetic transaminase, serum glutamic-pyruvic transaminase, serum aldolase, blood clotting tests (partial prothrombin time, prothrombin time, fibrin polymerization time). The following tests were abnormal: hemogram (r.b.c.: $\quad 3,900,000 / \mathrm{mm}^{3}$; w.b.c.: $4,500 / \mathrm{mm}^{3}$; Hb: $11.5 \mathrm{~g} / 100 \mathrm{ml}$; $\mathrm{Ht}: 32.8$ : $\mathrm{N}: 12 \%, \mathrm{E}: 2 \% ; \mathrm{L}: 81 \% ; \mathrm{M}: 5 \%$ ); lactic dehydrogenase: $635 \mathrm{~m} \mu / \mathrm{ml}$ (normal up to $250 \mathrm{~m} \mu / \mathrm{ml}$ ); acid phosphatase: $17 \mathrm{~m} \mu / \mathrm{ml}$ (normal up to $11 \mathrm{~m} \mu / \mathrm{ml}$ ); alkaline phosphatase: $219 \mathrm{~m} \mu / \mathrm{ml}$ ) (normal up to 170 $\mathrm{m} \mu / \mathrm{ml}$ ); prothrombin activity: $60 \%$; fatty free acids $0.83 \mathrm{M} \%$ (normal: $0.09-0.6$ M\%); serum electrophoresis: albumin $56 \%$, globulin $\alpha_{1} 1.7 \%$, globulin $\alpha_{2}$ $13.8 \%$, globulin $\beta 14.6 \%$, globulin $\alpha$ $13.9 \%$; serum carnitine: $1.30 \mathrm{nM} / \mathrm{ml}$ (normal: $2.5-7 \mathrm{nM} / \mathrm{ml}$ ). X-rays of cranium and thorax were normal. EEG showed an excessive amount of theta and also delta activity in the occipital regions, especially in the left cerebral hemisphere. Electromyography of the right quadriceps, right biceps, and right tibialis anterior at rest showed no fibrillation. On voluntary effort, motor unit potentials were of short duration, small amplitude, and polyphasic; a full interference pattern was often obtained, even during a slight contraction. Motor nerve conduction velocities were normal and repetitive stimulation revealed no electrical impairment of neuro-muscular transmission.

One month after admission there was a sudden worsening in the patient's condition. He vomited repeatedly and within a few hours became confused. The liver was greatly enlarged and the subsequent day he became comatose and died.

\section{MATERIALS AND METHODS}

\section{Muscle biopsies}

Biopsy specimens of gastrocnemius muscle were obtained from both patients. Portions were frozen and kept at $-80^{\circ} \mathrm{C}$ until carnitine levels were determined by the Fritz and Marquis method (1963). Cryostat sections were prepared and a series of histological and histochemical reactions performed (hematoxylin and eosin, modified trichrome, nicotinamide adenide nucleotide dehydrogenase (NADH), succinicodehydrogenase (SDH), ATPase at a $\mathrm{pH}$ of 9.4, 4.6 4.3; PAS, phosphorylase, acid phosphatase, Oil red O. A sample of muscle tissue was fixed in $2.5 \%$ glutaraldehyde buffered at pH 7.4 with cacodylate buffer for 20 hours at $4^{\circ} \mathrm{C}$ and post-fixed in $2 \%$ buffered osmium tetroxide. The material was then embedded in Spurr. The thin sections for electron microscopy were stained with uranyl acetate and lead citrate. 
Nerve biopsy

In case 1, a biopsy of the sural nerve was performed. The specimen was treated for electron microscopy as the muscle sample.

\section{Liver biopsy}

In case II, a liver biopsy was obtained by a percutaneous needle puncture for histological and histochemical study (Oil red O; PAS; hematoxylin and eosin).

\section{Exercise tests}

Subject C.M. - Exercise tests were carried out on a bicycle ergometer (Monark-Crescent AB, Varberg, Sweden) at a work load of 300 $\mathrm{kpm} / \mathrm{min}$. The load was about $60 \%$ of the subject's maximal aerobic power ( $\dot{\mathrm{V}}_{2}$ max), indirectly measured (Margaria et al., 1965) in a separate session. The effort was maintained without any subjective discomfort for about 30 minutes. Four normal subjects of about the same anthropometric characteristics and training condition volunteered as controls.

Subject P.T. - As extended exercise on the bicycle was not possible, a bench $20 \mathrm{~cm}$ high was preferred as an ergometer. The subject performed full knee bends at the bench for 5-7 minutes at a rate of 10,15 and 25 times/min. following a rhythm imposed by a metronome. The exercise intensities were about 0.4-0.5 and 0.7 $\dot{\mathrm{VO}} 2 \mathrm{max}$, respectively. (Margaria et al., 1965). Normal values previously collected were used (Scarlato et al., 1977) as controls.

At rest and at $10 \mathrm{~min}$ intervals for patient C.M. (last minute of exercise for subject P.T.) the expired air was collected in a spirometer. Subsequent analysis of $\mathrm{O}_{2}$ and $\mathrm{CO}_{2}$ concentrations (Polarographic $\mathrm{O}_{2}$ analyzer, Instrumentation Laboratory, Milan, Italy and infrared $\mathrm{CO}_{2}$ meter, Godart N.V., De Bilt (U), Holland) were performed to calculate oxygen consumption $\left(\mathrm{V}_{2}\right)$ by the conventional open circuit method. Furthermore, in subject C.M. $\dot{\mathrm{VO}}_{2}$ was determined in the first 2 hours of recovery at $30 \mathrm{~min}$ intervals. Venous blood samples were taken from the cubital vein, at regular intervals, during the $30 \mathrm{~min}$ exercise for patient

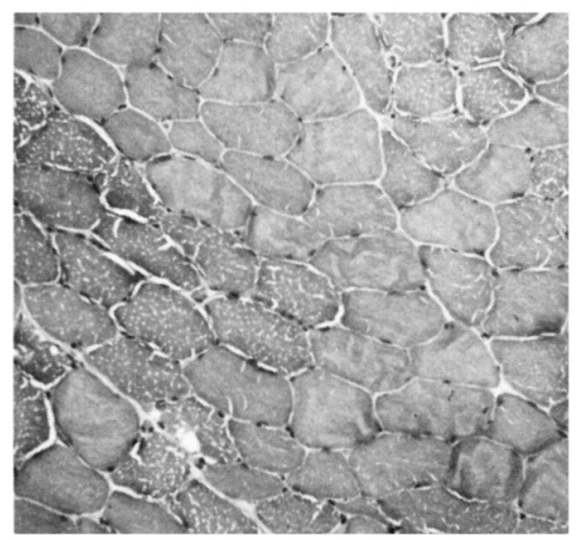

Figure 1-Presence of numerous vacuoles in one type of muscule fiber. Hematoxylin-Eosin. Original magnification $100 \mathrm{x}$.

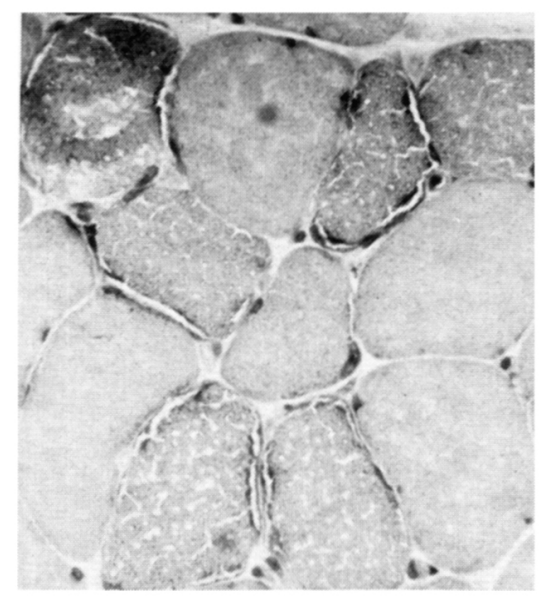

Figure 2-Subsarcolemmal collections of rimmed material with Gomori's stain. Original magnification $250 \mathrm{x}$.

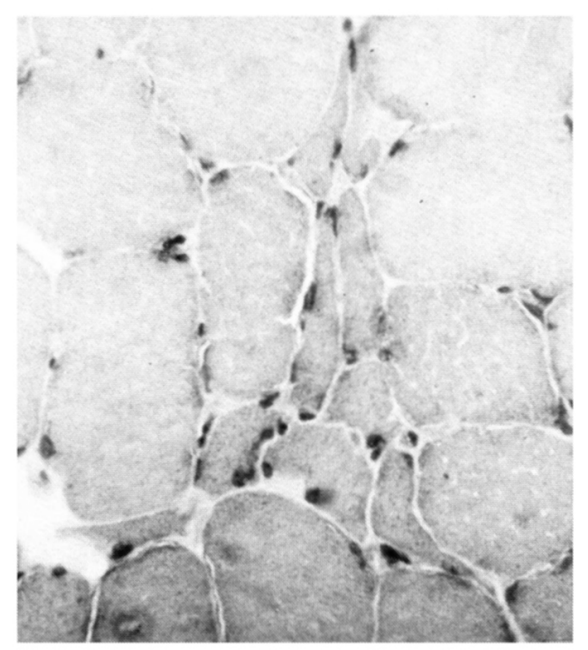

Figure 3-Small groups of angulated and hýpotrophic fibers in case two. Trichrome Gomori $250 \mathrm{x}$.
C.M. For patient P.T., blood was drawn 5 min after the end of each exercise period, according to the procedure of Margaria et al. (1963). The concentration of the following metabolites was determined in blood: glucose, lactic acid, pyruvic acid, free fatty acid and ketone bodies. Heart rate was measured by an electrocardiograph.

\section{RESULTS}

Histology and Histochemistry of muscle biopsy

With hematoxylin-eosin and modified Gomori trichrome stains, two types of fibers could be distinguished in both cases: one appeared normal, while the other contained numerous abnormal empty spaces (Figure 1) and, sometimes, a subsarcolemmal collection of red material, giving the appearance, with Gomori stain, of ragged red fibers (Figure 2 ). In the first patient (C.M.), there were also small groups of hypotrophic and angulated fibers (Figure 3 ). Connective tissue and blood vessels were normal. ATPase reactions showed that small vacuoles occurred in most type I fibers (Figure 4); in the first case some vacuolated fibers were of type II (Figure 5). These vacuoles stained positively with ORO and SBB, indicating the presence of neutral fat and acid lipids (Figure 6); SDH and NADH reactions showed increased activity, especially in the subsar-

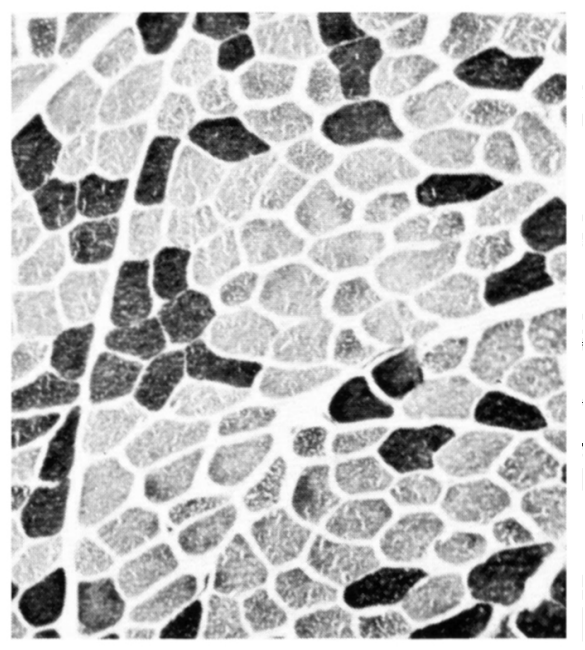

Figure 4-Small vacuoles are present only in type I fibers. ATPase reaction, $\mathrm{pH}$ 9.4. Original magnification $100 \mathrm{x}$. 


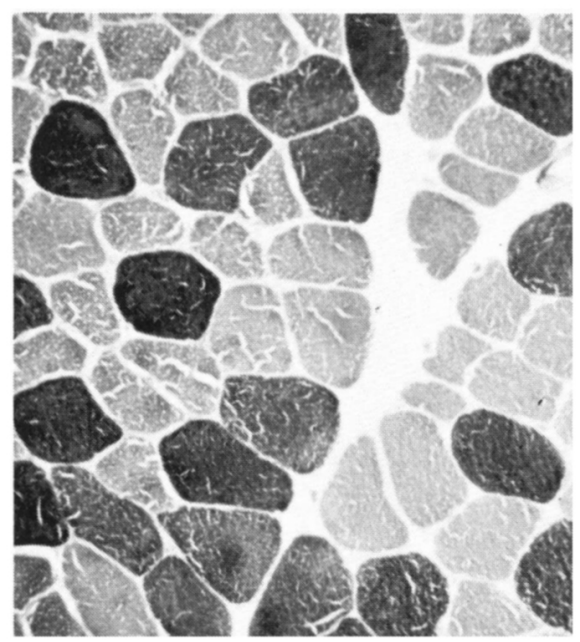

Figure 5-A few vacuoles are present also in type II fibers. Case one. A TPase reaction, $\mathrm{pH} 9.4$. Original magnification $250 \mathrm{x}$.

colemmal areas (Figure 7). Histographic analysis demonstrated in both cases more than $70 \%$ of gastrocnemius and vastus lateralis muscle fibers were of type I (Figure 8 and 9). In the second patient (P.T.), both fiber types were atrophic, especially the first type (Figure 9).

\section{Ultrastructure}

Ultrastructure examination showed collections of vacuoles of variable size in the majority of type I fibers. These vacuoles were gener-
Figure 6-Accumulation of lipid droplets in type I fibers. Oil-Red $O$ reaction. Original magnification $250 \mathrm{x}$.

ally empty, often bounded by a rim of osmiophilic material, sometimes showing coalescence, giving the appearance of lipid droplets. They were arranged in clusters or in parallel rows both below the sarcolemmal membrane and in the intermyofibrillar spaces. The myofibrils were often disrupted and displaced (Figure 10). In both cases, there were clusters of mitochondria in subsarcolemmal and intermyofibrillar regions, associated with lipid vacuoles (Figure 11), sometimes containing paracrystalline in-

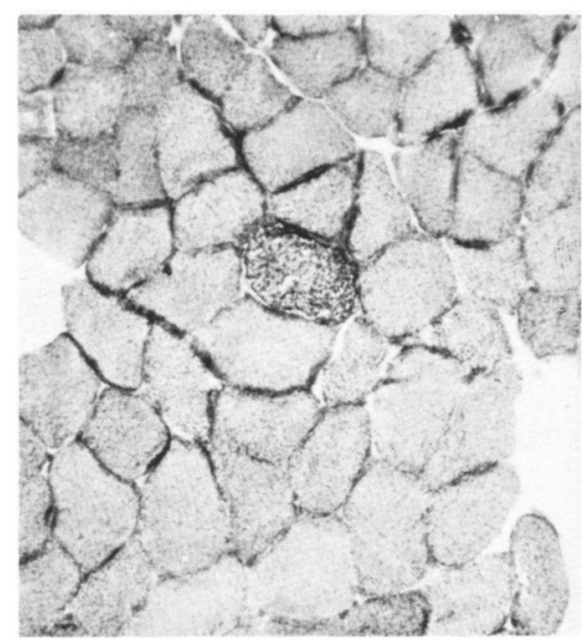

Figure 7-Increase of NADH activity below sarcolemmal membrane. Original magnification $250 \mathrm{x}$.

clusions (Figure 12). These mitochondria were often abnormal in shape and size; mitochondrial abnormalities were also present in some fibers which did not exhibit accumulations of lipid droplets. Lipidmitochondrial abnormalities were often associated with an increase in glycogen granules, especially in case two (Figures 13 and 14).

\section{Liver biopsy}

Histological examination in case two revealed a large number of vac-

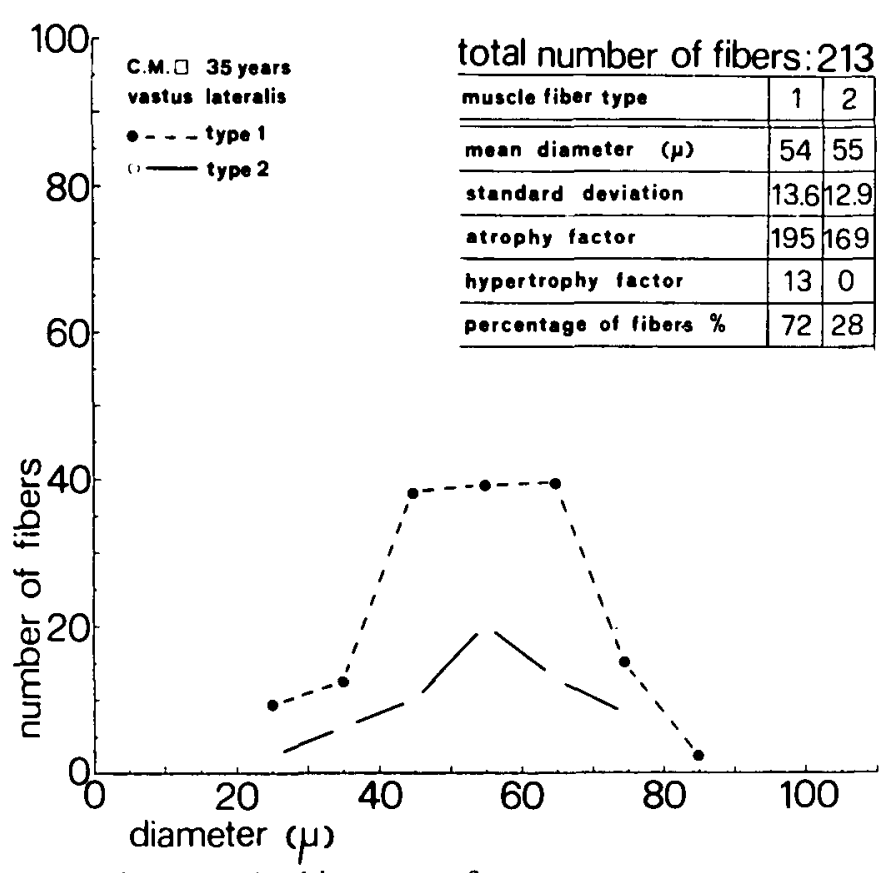

Figure 8-Muscular histogram of case one.

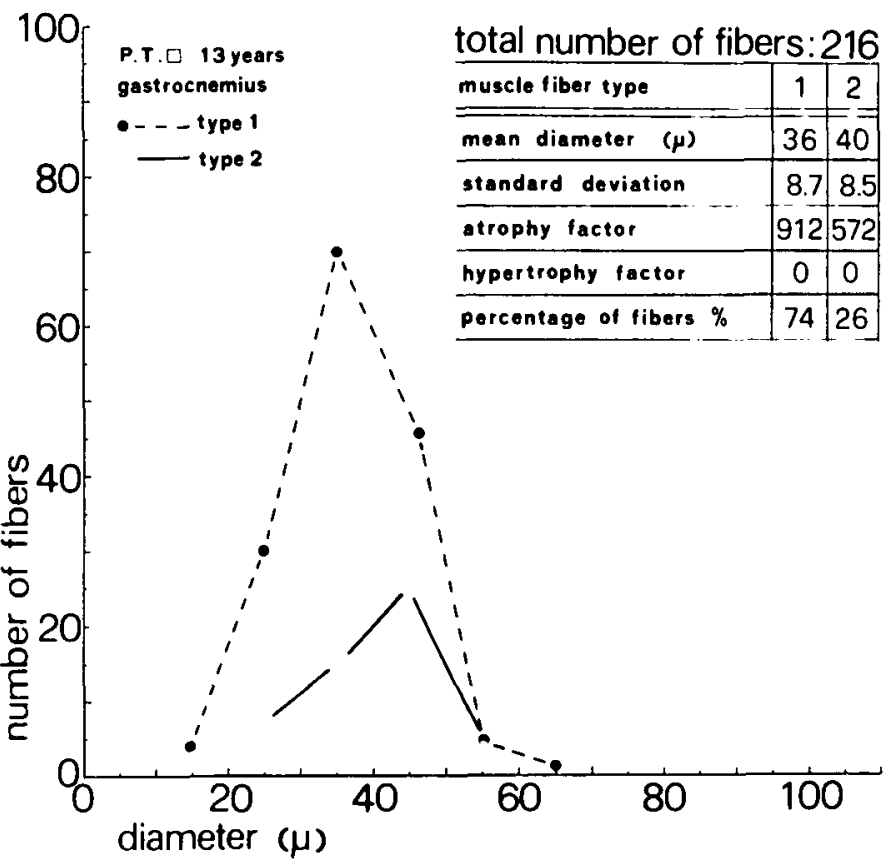

Figure 9-Muscular histogram of case two. 


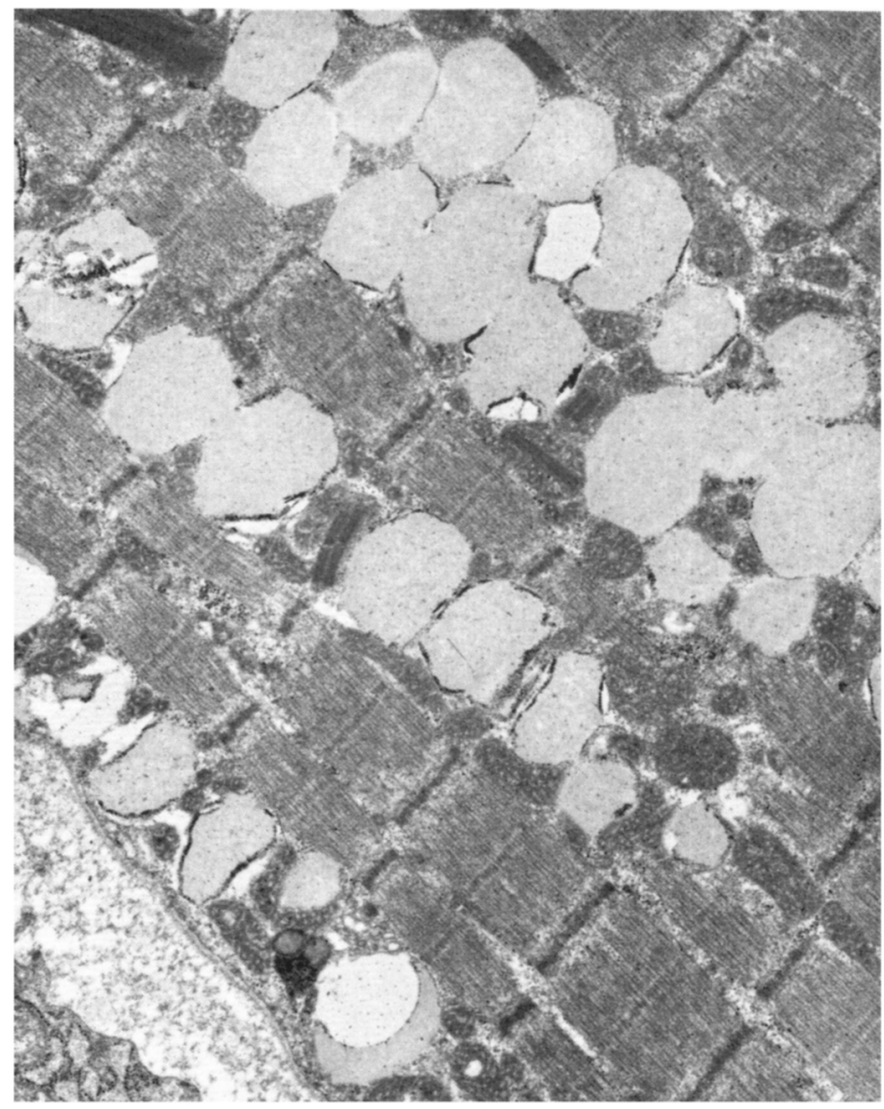

Figure 10-Accumulation of lipid droplets between myofibrils and beneath sarcolemmal sheath. Note crystalline inclusions in some mitochondria. Original magnification $12500 \mathrm{x}$.

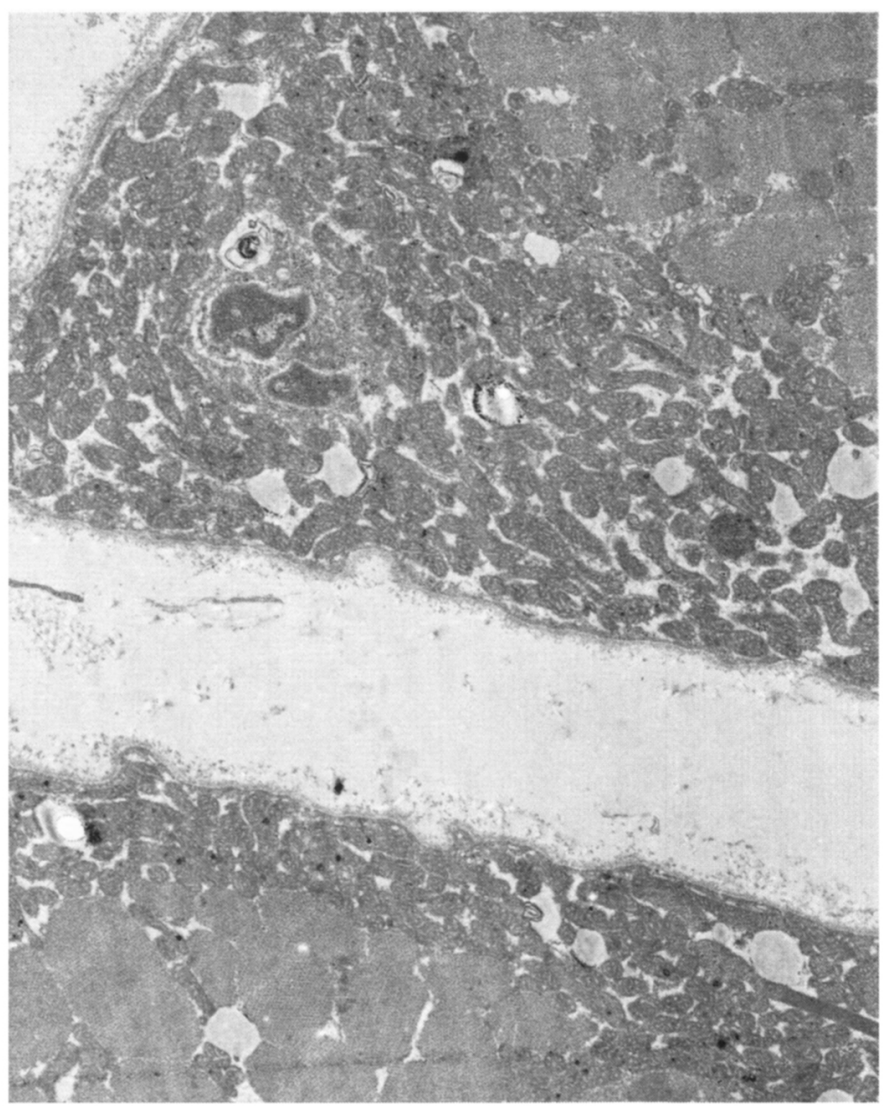

Figure $11-$ Cluster of mitochondria in subsarcolemmal regions. Original magnification $6800 \mathrm{x}$. uoles of various size in liver cells, especially at the periphery of the hepatic lobule. These vacuoles were

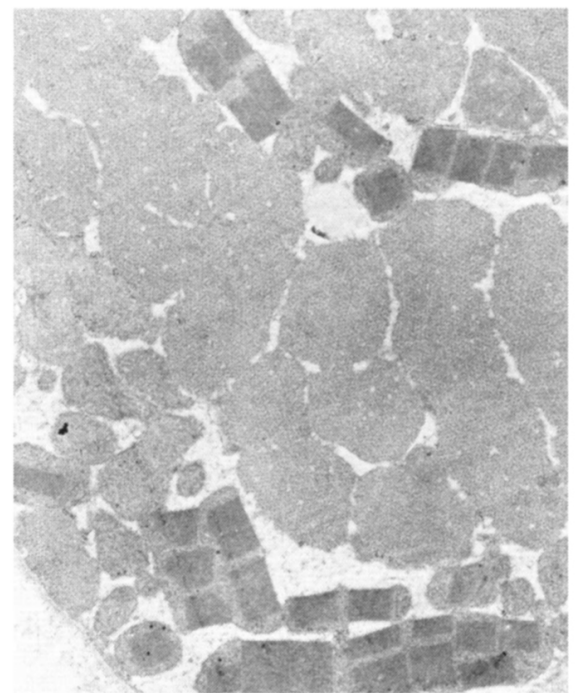

Figure 12-Accumulation of mitochondria with crystal-like inclusions. Original magnification $12500 \mathrm{x}$. strongly positive to Oil Red $O$ reactions, thus demonstrating an accumulation of lipidic material (Figure 15).

\section{Nerve biopsy}

In the first patient, the ultrastructural examination of the sural nerve revealed a moderate loss of myelin sheaths; no significant abnormality was noted inside the cytoplasm of Schwann's cell.

\section{Biochemical investigations}

In both cases, the concentration of serum and muscle carnitine was determined according to the method described by Di Mauro et al. (1973), with minor modifications. The following values were found:

\section{plasma muscle $(\mathrm{nM} / \mathrm{ml}) \quad(\mathrm{nM} / \mathrm{mg}$ prot.)}

$\begin{array}{lll}\text { case I } & 1.48 & 2.75 \\ \text { case II } & 1.30 & 2.50\end{array}$

controls $\quad 2.50-7.00 \quad 9.00-18.00$
Metabolic and biochemical responses to exercise

Case 1 (C.M.) - The oxygen consumption at rest, during $35 \mathrm{~min}$ of exercise, and in the following $120 \mathrm{~min}$ of recovery, together with the corresponding lactic acid concentrations in blood are given in Figure 16. After the sudden initial increase, $\dot{\mathrm{V}} \mathrm{O}_{2}$ tended to be constant, within the normal range, for the entire remaining period of exercise, indicating a steady state in respect to $\dot{\mathrm{VO}}$. During recovery, a sudden decrease of $\dot{\mathrm{V}} \mathrm{O}_{2}$ took place within a few minutes, with resting conditions for the next 2 hours. After about $10 \mathrm{~min}$ of exercise, the heart rate became $145 \mathrm{~b} / \mathrm{min}$ (same figure); it increased slightly thereafter, reaching about $155 \mathrm{~b} / \mathrm{min}$ at the end of exercise. This continuous increase after the first min of exercise can be attributed to a rise of core temperature as a result of the exercise (Mostardi et al., 1974). During recovery, the heart rate returned to resting values within $5-10 \mathrm{~min}$. 

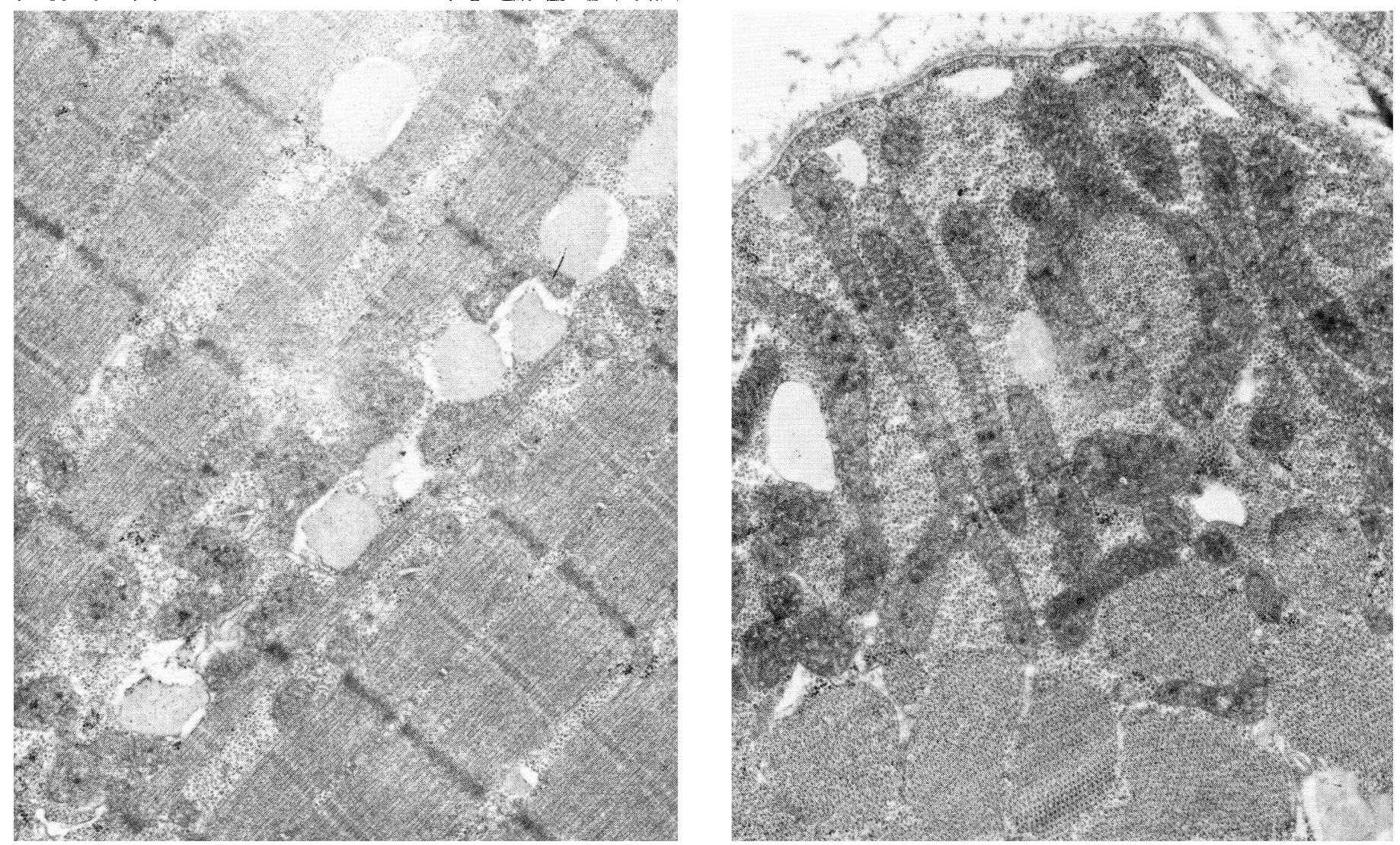

Figures 13 and 14-Excess of glycogen between lipid droplets and mitochondria, both in intermyofibrillar and subsarcolemmal regions. Original magnification $12500 \mathrm{x}$.

Similar findings are usual in normal sedentary subjects. The respiratory quotient $\left(\mathrm{CO}_{2}\right.$ production/ $\mathrm{O}_{2}$ consumption) rose from 0.82 at rest to 1.1 during the whole period of exercise, returning to resting values after 10 min of recovery. The lactic acid concentration in blood (same figure) showed a sudden increase of about 30 $\mathrm{mg} \%$ in the first $5 \mathrm{~min}$ of exercise (i.e., $6 \mathrm{mg} \%$ per $\mathrm{min}$ ). After this initial rise, the blood L.A. concentration increased at a slower rate $(2.5$ mg\% per min) until the end of the exercise. This rate of accumulation of L.A. in blood was equivalent to an energy yield of about $50 \mathrm{ml} \mathrm{O} 2 / \mathrm{min}$ (Margaria et al., 1963). The time course of the disappearance of L.A. from the blood in recovery was within the normal range $(\mathrm{t} 1 / 2=15-18$ $\mathrm{min}$ ). Blood pyruvate, from normal resting value, reached a plateau after $20 \mathrm{~min}$ of exercise at a level slightly higher than expected for this work intensity. After exercise, blood pyruvate returned to resting levels in about $90 \mathrm{~min}$. The $\mathrm{LA} / \mathrm{PA}$ ratio, which was about 30 at rest, rose progressively during the working period to an upper value of about 60 at the end of the exercise (Figure 18). These LA/PA values, particularly those observed at the end of exercise, seem extremely high, especially in view of the relatively low exercise level.

Blood glucose concentration, which was normal ( $75 \mathrm{mg} \%)$ at rest, showed a transient initial increase, followed by a continuous decrease until the end of the exercise ( 70 $\mathrm{mg} \%$ ). It increased again in recovery to a peak about $80 \%$ higher than resting after about 1 hour. This is the opposite of what may be expected in normal subjects. The FFA concentration $(80 \mu \mathrm{M} \%)$ at rest) was practically unchanged during the entire period of exercise and for the first 30 min of recovery. A marked increase in FFA (up to $120 \mu \mathrm{M} \%$ ) took place about 1 hour after the end of the exercise, again at variance with the normal. Ketone body concentration, from a resting value of $0.31 \mathrm{mg} \%$, doubled during exercise, decreased to about normal values during the initial recovery period and increased again (to $0.70 \mathrm{mg} \%$ ) about $60 \mathrm{~min}$ after the end of exercise.

Case 2 (P.T.) - The $\mathrm{O}_{2}$ uptake above resting $\left(\triangle \dot{\mathrm{VO}}_{2} \mathrm{ml} / \mathrm{min}\right)$ and the L.A. accumulation rate in the body ( $\triangle \mathrm{L} A \mathrm{mg} \%$ per min) together with the sum of the two $\left(\mathrm{VO}_{2}+\dot{V}_{2} \mathrm{LA}\right.$, the L.A. being converted to its $\mathrm{O}_{2}$ equivalent (Margaria et al., 1963) are indicated in Figure 17 as a function of the intensity of exercise (in $\mathrm{kpm} / \mathrm{min}$ ). Within the investigated range, both $\dot{\mathrm{O}}_{2}$ and L.A. production increased linearly with the work load. These blood L.A. concentrations were about 2-4 times larger than in normal subjects for similar intensities and durations of exercise. The absolute value of overall energy expenditure $\left(\mathrm{VO}_{2}+\dot{\mathrm{VO}} 2 \mathrm{LA}\right)$ was within the upper normal range for this intensity of exercise. The respiratory quotient rose from a value of 0.93 at rest to 1.06-1.16 during exercise, independently of the work intensity. During recovery, it returned to rest- 


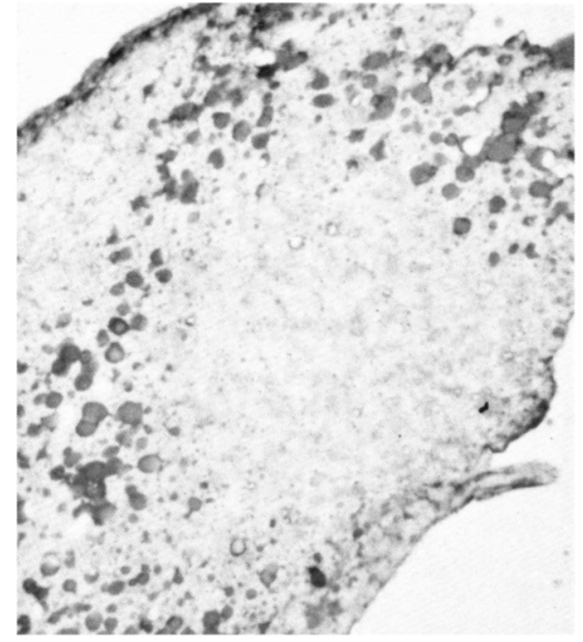

Figure 15-Accumulation of lipid droplets of various size in liver cells, especially at the periphery of the hepatic lobule. Oil-Red $O$. Original magnification $100 \mathrm{x}$

ing values within $10 \mathrm{~min}$. Steady state heart rate increased from $113 \mathrm{~b} / \mathrm{min}$ (lightest exercise) to $160 \mathrm{~b} / \mathrm{min}$.

\section{DISCUSSION}

Some differentiating features of our cases must be emphasized. In the first patient, muscular weakness began in adult life; there was no muscular hypotrophy, but great fatigabil- ity and early muscular exhaustion even after slight exercise. Cramps were present during exercise and suggested a metabolic myopathy. The pattern of muscular weakness was predominantly proximal with myopathic distribution. The course of the illness was favorable and the treatment with carnitine led to a progressive recovery of muscular strength.

In the second case, the disease started in childhood; the symptoms and signs were those of a generalized disease, with a fluctuating course and intermittent acute episodes of hypoglycemia, coma and vomiting; notable hepatic enlargement and electroencephalographic modifications were also present. In this case, the course of the illness was unfavorable and the patient died after an episode of hypoglycemia and coma.

The contrast between the two clinical pictures was striking, especially if the overlap of muscle histopathology and the lowering of serum and muscular carnitine is considered. However, it is evident from the published cases of lipid storage disease with carnitine deficiency that such different clinical pictures might have similar biochemical and his- topathological alterations. In the majority of patients, the illness began in childhood (Van Dyke et al., 1975; Karpati et al., 1975; Bank et al., 1975; Boudin et al., 1976; Angelini et al., 1976; case 2 of Cornelio et al., 1977; Engel et al., 1977), but it can , as in our first case, begin in adult life (Markesbery et al., 1974; case 1 of Cornelio et al., 1977; Isaacs et al., 1976) or in adolescence (Engel and Angelini, 1973; case 3 of Cornelio et al., 1977). The involvement of different organs and tissue is also extremely variable; only muscular (Angelini et al., 1976; Isaacs et al., 1976), hepatic and muscular (Engel and Angelini, 1973; Markesbery et al., 1974), cardiac (Van Dyke et al., 1975), or generalized (Karpati et al., 1975; Cornelio et al., 1977; and Engel et al., 1977). In the latter condition, the course of the illness may be fatal (Cornelio et al., 1977; Engel et al., 1977). The wide range of clinical manifestations seems to be an important feature of this syndrome; it could be the expression of different penetrance of the pathogenic gene, but a second unknown metabolic defect, in addition to carnitine deficiency, cannot be excluded.

The muscle biopsies showed a
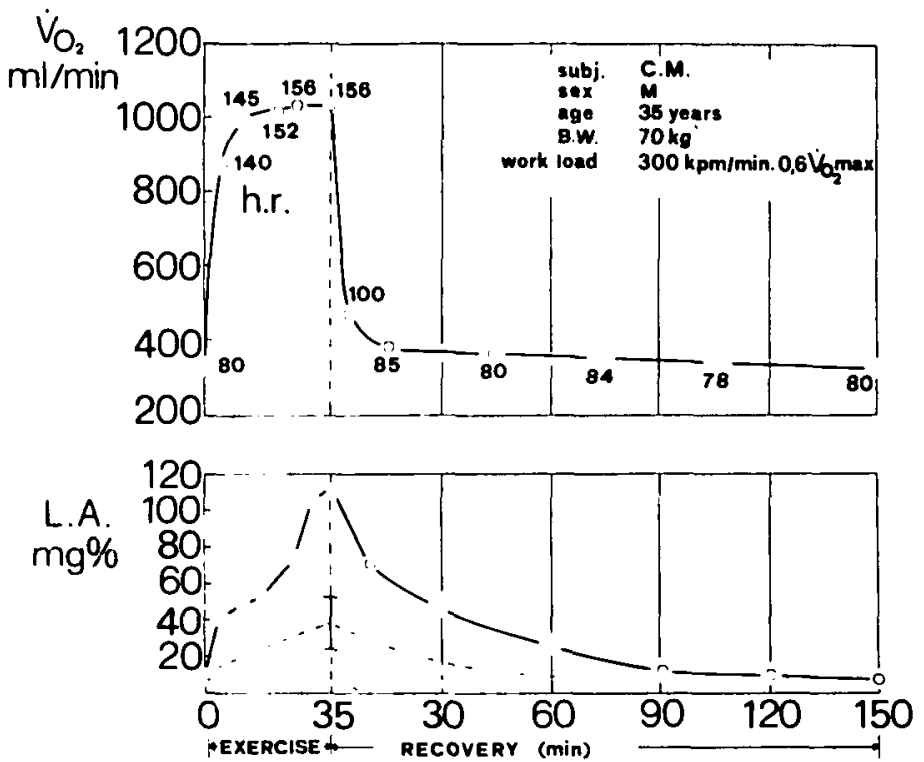

Figure 16-Oxygen consumption ( $\mathrm{VO}_{2}, \mathrm{ml} / \mathrm{min}$ ) and blood lactic (L.A., mg\%) and concentration during $35 \mathrm{~min}$ of exercise and 150 min of recovery. Heart rate (h.r.) is also indicated at regular intervals (Case 1, subject C. M.).

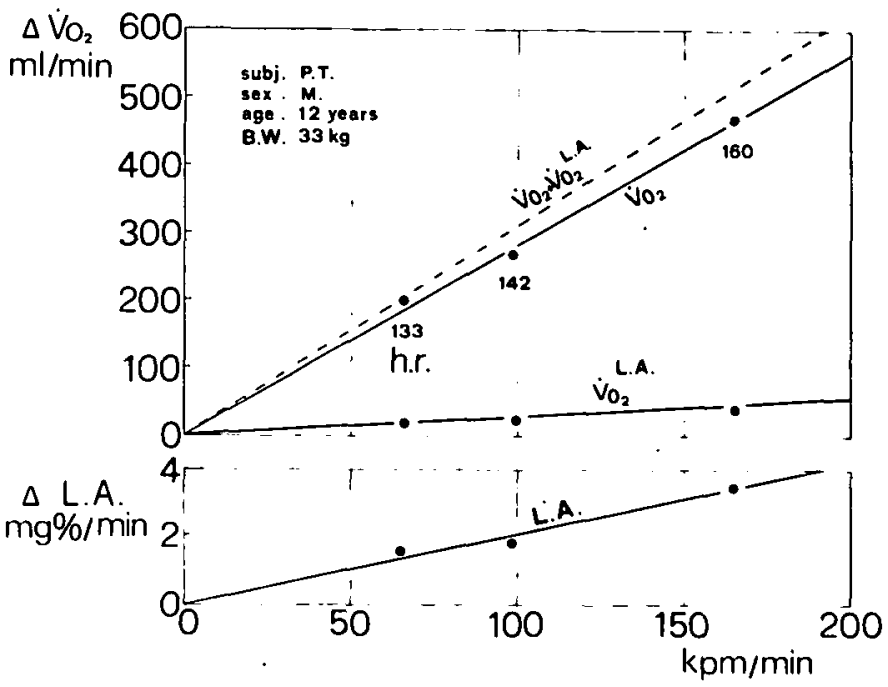

Figure $17-\mathrm{O} 2$ consumption over resting value $(\Delta \vee \mathrm{V} 2, \mathrm{ml} / \mathrm{min})$ and rate of lactic acid increase in blood $(\Delta L A, \mathrm{mg} / 100 \mathrm{~m} / \mathrm{per}$ $\mathrm{min}$ ) as a function of the intensity of the exercise (in $\mathrm{kgm} / \mathrm{min}$ ). Heart rate values are also shown. The continuous line labelled as $\dot{V} \mathrm{O}_{2} \mathrm{LA}$ gives the $\mathrm{O}_{2}$ equivalent of $\dot{L}$. A. accumulated in the body, calculated from Margaria et al. (1963). Dashed line $\left(\dot{\mathrm{V}}_{2}+\dot{\mathrm{V}} \mathrm{O}_{2} \mathrm{~L} A\right)$ indicates the overall energy consumption given as $\mathrm{O}_{2}$ equivalent. 


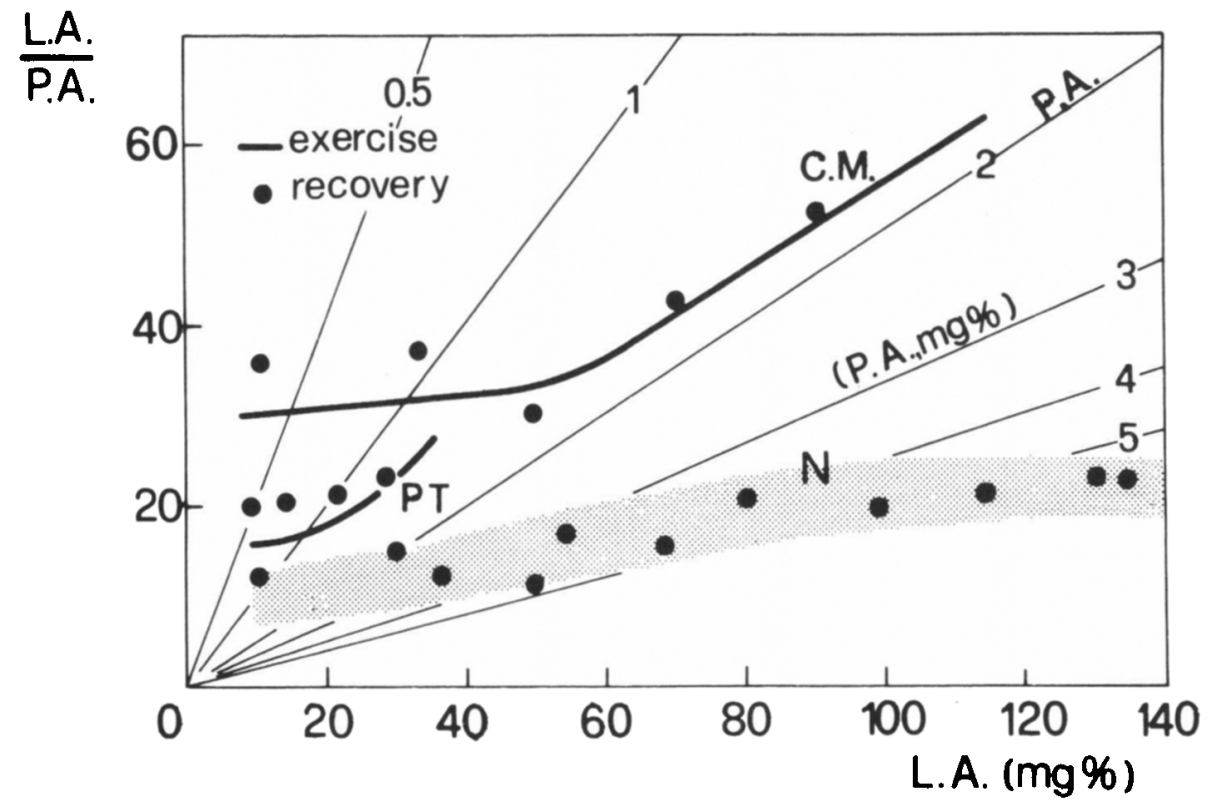

Figure 18- Lactic acid/pyruvic acid ratio (LA/PA) as a function of lactic acid blood contraction (L.A. $\mathrm{mg} \%$ ). Continuous lines indicate the relationship found during exercise, while the full dots give the same values during recovery. Dashed area shows the values for controls and during heavy exercise (Margaria et al., 1963). The lines radiating from the origin indicate the pyruvic acid blood concentration (in $\mathrm{mg} \%$ ).

clear distinction between two kinds of fibers; the first was within normal limits, the second exhibited an accumulation of neutral fat in subsarcolemmal and intermyofibrillar spaces. In the second patient, these pathological fibers were all type I, as in the case described by Karpati et al. (1975), Angelini et al (1976), and Isaacs et al. (1976). In the first patient, slight collections of lipid droplets were also present in some type II fibers, as observed by Engel and Siekert (1972) and Van Dyke et al. (1975). The most obvious reason for this selective storage of lipid material is that type I fibers are probably more dependent on lipid metabolism for energy demand than type II (Engel and Siekert, 1972).

In the first case, trophic changes were minimal, perhaps due to the recent onset of the disease. In the second case, there was clear atrophy of both types of fibers. This was more evident in type $\mathrm{I}$, in line with the preferential storage of neutral fats in this type of muscle fiber. Many of these abnormal fibers stained red with Bomori's trichrome, especially under the sarcolemmal membrane similar to "ragged-red fibers". The presence of numerous ragged-red fibers was first reported by Karpati et al. (1975).

In both patients, the clear type I predominance as demonstrated by histographic analysis is surprising. This finding is difficult to explain in relation to the selective storage of lipid material in these fibers. Predominance of type I fibers is also reported by Slavin et al. (1975) in a case of neutral lipid storage disease with ichthyosis, and by Cornelio et al. (1977) in an analogous case without ichthyosis. In both our patients, there was also an alteration of topographic distribution of the muscle fibers, with a "type grouping' supporting the existence of a neurogenic involvement. This was also suggested, at least in the first case, both histologically (Figure 3) and by EMG examination. The neurogenic involvement is not entirely surprising since Markesbery et al. (1974) demonstrated lipid droplets in Schwann's cell of the sural nerve.

In addition to lipid storage, the ultrastructural examination showed collections of mitochondria under sarcolemma and between myofibrils, giving the appearance of "pleioconial myopathy" (Shy et al., 1966). Mitochondria of various size and shape in isolation or groups, with paracrystalline inclusions were also visible. These morphologic changes of mitochondria have been observed with increasing frequency in recent years (Boudin et al., 1976; Isaacs et al., 1977; Engel et al., 1977) and are an important feature of the ultrastructural pathology of this myopathy. As far as the origin of these inclusions is concerned, it must be stressed that camitine is an essential cofactor in the transfer of long-chain fatty acids to mitochondria, where they are oxidized by the process of betaoxidation (Fritz and Yue, 1963; Newsholme and Start, 1973). Hence, it may be suggested that an alteration in mitochondrial metabolism, arising from a carnitine deficiency, could be responsible both for mitochondrial proliferation and for the presence of crystal-like substances inside the mitochondria.

Cytochemical studies by Bonilla et al. (1975) prove that crystalline inclusions are inactive structures devoid of some enzymatic activities, such as cytochrome $\mathrm{C}$ oxidase and carnitine acetyltransferase. Because serum carnitine was below normal values in both patients and, at least in the second case, there was marked liver enlargement with lipid storage, it seems likely that the carnitine deficiency arose from impaired biosynthesis in the liver cells.

During exercise, the amount of $\mathrm{O}_{2}$ consumed per unit time in both patients, in relation to the intensity of the exercise was within the expected range. The production of lactic acid was appreciably increased. This is probably due to an impairment in the utilization of fatty acids as fuel, as indicated by the large droplets found in muscle. In line with this interpretation are:

1) the decreased blood glucose concentration during exercise, at least in case 1, indicating an increased glucose utilization by the working muscle, and

2) a high respiratory quotient, in spite of normal ventilation.

The overall energy output (aerobic and lactacid) appears to be higher than in controls. This, together with the mitochondrial alterations observed in muscle fibers, may indicate, according to Di Mauro et al. 
(1973), Sulaiman et al. (1974), and Schotland et al. (1976) an alteration or loss of some enzymes of the tricarboxylic cycle, a decrease in respiratory rate, and a reduction in ATPase activity. This suggest a "loosely coupled" oxidative phosphorylation. Furthermore, the mitochondrial alterations observed (Figures 10, 11, 12) may be responsible for the abnormally high LA production in these patients compared to the controls. If this is true, a fraction of the total amount of ATP necessary for muscular contraction must be provided in the extra mitochondrial space, i.e., by glycolytic enzymes. Such a mechanism is also supported by similar findings during muscular exercise in oculo-cranio neuromuscular disease (Reske-Nielsen et al., 1976; Scarlato et al., in press), a pathological condition where the same mitochondrial alterations in muscle fibers also occur.

More direct evidence along these lines is provided by the higher LA/PA for a given LA concentration observed in these patients (Figure 18) compared to the normal values found in controls as reported by Margaria et al. (1963). As the LA/PA ratio is a measure of the red-ox state of the tissue, the above findings suggest that in these patients the respiratory chain is impaired, leading to an abnormal accumulation of reduced NAD in the cytoplasma and hence to an abnormally high LA concentration, in respect to the PA concentration.

The overproduction of LA in this disease could also be explained by the hypothesis of Childress et al. (1966) on the metabolic function of carnitine in the fatty acid oxidase deficient flight of the blow-fly. These authors found that carnitine affects carbohydrate utilization, increasing the rate of oxidative decarboxylation of pyruvate to acetyl-CoA. A carnitine deficiency could determine an increase in pyruvate and, hence, lactic acid. This hypothesis, however, does not explain the abnormal LA/PA ratios observed in these patients. It would be interesting to test the effect of carnitine on carbohydrate metabolism in man, since we noted, ultrastructurally, an increase in glycogen granules in our second patient's muscle tissue.

\section{ACKNOWLEDGEMENT}

Thanks are due to E. Rossi and M. A. Bergo for their skillful technical assistance.

\section{REFERENCES}

ANGELINI, C., PIEROBON, S., LUKE, S., and CANTARUTTI, F. (1976). Camitine deficiency: report of a treated case. Neurol. 26: 633-637.

BANK, W. J., DI MAURO, S., BONILLA, E., CAPUZZI, D. M. and ROWLAND, L. P. (1975). A disorder of muscle lipid metabolism and myoglobinuria. N. Engl. J. Med. 292: 443-449.

BONILLA, E., SCHOTLAND, D. L., DI MAURO, S. and ALDOVER, B. (1975). Electron cytochemistry of crystalline inclusions in human skeletal muscle mitochondria. J. Ultrast. Res. 5I: 404-408.

BOUDIN, G., MIKOL, J., GUILLARD, A. and ENGEL, A. G. (1976). Fatal systemic carnitine deficiency with lipid storage in skeletal muscle, heart, liver and kidney. J. Neurol. Sci. 30; 313-325.

CHILDRESS, C. C., SACKTOR, B. and TRAYNOR, D. R. (1966). Function of carnitine in the fatty acid oxidase-deficient insect flight muscle. J. Biol. Chem. 242: 754-760.

CORNElio, F., DI DONATO, S., PELUCCHETTI, D. BIZZI, A., BERTAGNOLIO, B., D'ANGELO, A. and WIESMANN, U. (1977). Fatal cases of lipid storage myopathy with carnitine deficiency. J. Neurol. Neuros. Psych. 40: 170-178.

DI MAURO, S., SCHOTLAND, D. L., BONILLA, E., LEE, C. P., GAMBETTI, P.' L. and ROWLAND, L.P. (1973). Progressive ophthalmoplegia, glycogen storage and abnormal mitochondria. Arch. Neurol. 29: $170-173$

ENGEL, A. G. and ANGELINI, C. (1973). Carnitine deficiency of human muscle with associated lipid storage myopathy: a new syndrome. Science 179: 899-902.

ENGEL, A. G., BANKER, B. Q. and EIBEN, R. M. (1977). Carnitine deficiency: clinical, morphological and biochemical observations in a fatal case. J. Neurol. Neuros. Psych. 40: 313-322.

ENGEL, A. G. and SIEKERT, R. G. (1972) Lipid storage myopathy responsive to prednisone. Arch. Neurol. 27: 174-181.

FRITZ, I. B. and YUE, K. T. N. (1963). Long-chain carnitine acyltransferase and the role of acylcarnitine derivates in the catalytic increase of fatty acid oxidation induced by carnitine. J. Lip. Res. 4: 279-280. ISAACS, H., HEFFRON, J. J. A., BADENHORST, $M$. and PICKERING, A. (1976). Weakness associated with pathological presence of lipid in skeletal muscle: a detailed study of a patient with carnitine de- ficiency. J. Neurol. Neuros. Psych. 39: 1114-1123.

KARPATI, G., CARPENTER, S., ENGEL, A. G., WATTERS, G., ALLEN, J., ROTHMAN, S., KLASSEN, G. and MAMER, O. A. (1975). The syndrome of systemic carnitine deficiency. Neurol. 25: 16-24.

MARGARIA, R., CERRETELLI, P., DI PRAMPERO, P. E., MASSARI, C. and TORELLI, G. (1963). Kinetics and mechanism of oxygen debt contraction in man. J. Appl. Physiol. 18: 371 .

MARGARIA, R., AGHEMO, P. and ROVELLI, E. (1965). Indirect determination of maximal $\mathrm{O} 2$ consumption in man. J. Appl. Physiol. 20: 1070.

MARKESBERY, W. R., MCQUILLEN, M. P., PROCOPIS, P. G., HARRISON, A. R. and ENGEL, A. G. (1974). Muscle carnitine deficiency. Association with lipid myopathy vacuolar neuropathy and vacuolated leucocytes. Arch. Neurol. 31: 320-324.

MOSTARDI, R., KUBIKA, R., VEICSTEINAS, A. and MARGARIA, R. (1974). The effect of increased body temperature due to exercise on the heart rate and on the maximal aerobic power. Europ. J. appl. Physiol. 33: 237-245.

NEWSHOLME, E. A and START, C. (1973). Regulation of metabolism. Wiley, London, page 20-21.

RESKE-NIELSEN, E., LOU, C. H. and LOWERS, M. (1976. Progressive external ophthalmoplegia. Acta Ophthal. 54: 553-573.

SCARLATO, G., PELlEGRINI, G. and VEICSTEINAS A. (in press). Morphologic and metabolic studies in a case of oculocranio-somatic neuromuscular disease. $J$. Neuropathol. Exper. Neurol.

SCHOTLAND, D. L., DI MAURO, S., BONILLA, E., SCARPA, A. and LEE, C. P. (1976. Neuromuscular disorder associated with a defect in mitochondrial energy supply. Arch. Neurol. 33: 475-479.

SHY, G. M., GONATAS, N. K. and PEREZ, M. (1966). Childhood myopathies with abnormal mitochondria. 1-Megaconial myopathy. 2-Pleoconial myopathy. Brain 89: $133-158$.

SLAVIN, G., WILLIS, E. J. RICHMOND, J. E., CHANARIN, I., ANDREWS, T. and STEWART, G. (1975). Morphological features in a neutral lipid myopathy. J. Clin. Path. 28: 701-710.

SMYTH, D. P. L., LAKE, B. D., MCDERMOT, J. and WILSON, J. (1975). Inborn error of carnitine metabolism (carnitine deficiency) in man. Lancet 1: 1198-1199.

SULAIMAN, W. R., DOYLE, D., JOHNSON, R. H. and JENNETT, S. (1974). Myopathy with mitochondrial inclusion bodies: histological and metabolic studies. J. Neurol., Neurosurg. and Psych. 37: 1236-1246.

VAN DYKE, D. H., GRIGGS, R. C., MARKESBERY, W. and DI MAURO, S. (1975). Hereditary carnitine deficiency of muscle. Neurol. 25: 154-159. 